\title{
PORTAL HYPERTENSION IN FIBROCYSTIC DISEASE OF THE PANCREAS
}

BY

\author{
JAMES B. GIBSON and H. W. RODGERS \\ From the Departments of Pathology and Surgery, Queen's University, Belfast
}

(RECEIVED FOR PUBLICATION MARCH 14, 1957)

It is now known that the liver is often damaged in fibrocystic disease of the pancreas. Bodian (1952) found patchy portal fibrosis and an increase in bileduct structures, which he termed focal biliary fibrosis, in half of the 50 cases in his series in which histological sections of liver were available. This lesion is found most often and most severely in older children, but Claireaux (1956) has recorded similar findings in the liver of a newborn infant with fibrocystic disease. The livers in Bodian's series were not deeply scarred and there was little evidence of portal hypertension. Pugsley and Spence (1949) reported a grossly nodular liver in fibrocystic disease with a normal spleen, but in a series of 116 patients with the disease Webster and Williams (1953) noted splenic enlargement in the five cases with clinical evidence of cirrhosis. Di Sant' Agnese (1955) recorded two instances of cirrhosis and portal hypertension among a number of cases with normal or partial pancreatic function, and a recent leading article in the British Medical Journal (1956) also draws attention to this complication, but it is rare. In the case presented here great enlargement of the spleen resulted from portal hypertension and necessitated treatment, although the primary condition was otherwise in a satisfactory state of control.

\section{Case Report}

A boy of 9 years was admitted to the Royal Belfast Hospital for Sick Children on October 17, 1956, for investigation of hepatosplenomegaly which had been discovered at a routine school medical examination. He weighed $56 \frac{1}{2} \mathrm{lb}$. and was a bright, energetic and intelligent school boy and had no complaints about his health. He is an only child and his careful and attentive mother remembered that when he was about 10 months old he had bulky, pale and offensive stools for a few weeks, but was healthy thereafter. His development continued but was slightly delayed. He had an attack of measles in 1952 and following this a moderately sharp attack diagnosed as 'pulmonary congestion' from which he made a rapid and apparently complete recovery.
In July, 1953, at the age of 6 , he was diagnosed as having coeliac disease. He had a distended abdomen, was under weight $\left(36 \frac{1}{2} \mathrm{lb}\right.$.) and passed frequent pale, bulky, greasy, foul-smelling stools. Trypsin was detected in the duodenal juice at $1 / 2,048$ dilution. The stools contained $43 \cdot 4 \mathrm{~g}$. $\%$ fat $(39 \cdot 1$ unsplit); the haemoglobin was $61 \%$ (Haldane). Neither chest nor alimentary radiographs showed any abnormality but clinically he was thought to have mild bronchitis. The liver was palpable 1 inch below the costal margin. The spleen was not felt. He was treated by a gluten-free, high-calorie, high-vitamin diet and, though not under any medical supervision, was free of complaints until the present admission to hospital in October, 1956.

On examination he was pale and the skin generally was slightly and patchily pigmented especially over the moderately protuberant abdomen. There was no jaundice; the fingers showed moderate clubbing. The liver was firm and easily palpable 2 inches below the costal margin. The spleen was large, firm and mobile, without pain; it reached to the mid-line and to the level of the umbilicus. Umbilical venous connexions were not detected on looking or listening and there was no evidence radiologically of oesophageal varices. There were no telangiectases and no nervous or other signs of hepatic failure. Plasma proteins and a bromsulphthalein test were within normal limits; zinc-sulphate flocculation was 5 units (normal 2.0) and serum alkaline phosphatase 43 K.A. units (normal up to 10). Seventy-two per cent. of an average fat intake was absorbed. Confirmation of the present diagnosis of fibrocystic disease was provided by the raised sweat electrolytes, namely sodium $113 \mathrm{mEq} . / 1$ (normal 10-80) and chloride $122 \mathrm{mEq} . / 1$ (normal 4-60). An attempt to obtain another specimen of duodenal juice was not successful. The chest showed signs of chronic bronchial infection clinically and radiologically. Glycosuria has never been found. Percutaneous splenic venography on November 6 showed a widely patent splenic vein without any of the tortuosity often seen in portal hypertension. In a portion of liver obtained by needle biopsy at the same time a moderate degree of fibrosis was found in some of the portal tracts which suggested that the splenomegaly was due to intrahepatic portal obstruction. The biopsy was similar to the subsequent one which is described below.

Laparotomy was carried out on November 23, and the 
liver was found to be moderately enlarged and much firmer than normal. There was a diffuse irregularity of the surface suggestive of widely distributed patches of scarring, but gross nodularity was not present. The portal venous system was prominent and the pressure in one of the inferior mesenteric radicles was $275 \mathrm{~mm}$. of saline, normal values by this method being up to 200 . The spleen was grossly enlarged, firm and congested. There was no free fluid in the peritoneal cavity. Splenectomy was performed. The pancreas was of normal size but unduly firm. Scattered over its surface were a number of nodular areas of lighter colour resembling foci of fat necrosis and one of these was removed for microscopical examination as well as a further needle biopsy of the liver. The gall bladder was normal. The patient recovered well from the operation but his convalescence was interrupted by a pulmonary infection. For nine days he had pyrexia, cough and sputum. It cleared up with tetracycline and it has not recurred.

Two months after operation he was very well and happy at school.

Pathology. The spleen (710 g.) was fleshy and had small depressions on its surface. Section showed many rust-coloured areas of irregular outline surrounding small arteries (Fig. 1) and containing a large proportion of fibrous tissue. These iron-incrusted Gamna-Gandy bodies stood out conspicuously against the rest of the splenic tissue, which showed other features of fibrocongestive splenomegaly. The portion of pancreas removed presented several peculiar histological features. It was characterized by extensive microcystic dilatation of the ducts and by numerous hyperplastic islets which were often partly traversed by ductules (Fig. 2). Acinar tissue with zymogen granules was present in small amounts (Fig. 3) but most of it appeared to have been lost; the fibrous tissue was moderately increased in amount. There was no inflammatory infiltrate. The ducts contained eosinophil masses of roughly laminated matter denser than normal secretion. The liver biopsy showed a marked degree of fibrosis of some of the larger portal tracts; other and smaller tracts in the biopsy were normal. The fibrous areas had well defined oval outlines and in some instances the portal vein seemed narrowed; there was a minor lymphocytic infiltration and a dilatation of small blood vessels. Small bile ducts were more numerous than normal in the fibrosed tracts but well differentiated. In one instance a number of dilated small ducts were grouped together (Fig. 4) suggesting focal biliary obstruction. Occasional fibrous strands were seen running from onè tract to another dividing the parenchyma irregularly; this was associated with an early stage of nodular regeneration of the parenchyma. There was no fatty infiltration.

\section{Discussion}

The scarring of the liver seen at operation was patchy and resembled that illustrated by Pugsley and Spence (1949) and by Webster and Williams (1953), although the process was more advanced in those fatal cases. In the fibrosed portal tracts small bile ducts were increased in number, though not to such a great extent as may occur in other forms of cirrhosis. Bodian (1952) considered an increase in bile-duct structures an essential element in the development of focal biliary fibrosis and explained the pathogenesis on the basis of localized obstructions of the bile ductules. Though our patient was not jaundiced, the elevation of the serum-alkaline phosphatase level, together with a less marked deviation of the zinc-sulphate-flocculation test, suggests some degree of biliary obstruction. Microcystic dilatation due to such an obstruction was seen in one of the biopsies and the process is illustrated also in the case of Pugsley and Spence (1949) where inspissated secretions plugged small ducts in the liver and where the gall bladder showed comparable changes. Fatty infiltration was absent in both of the biopsies taken here. Bodian (1952) found the incidence of fatty liver no greater in necropsies on fibrocystic disease than in fatal cases of other diseases and the evidence is against the view that fibrocystic disease brings about liver damage by causing a prolonged fatty infiltration. Fatty infiltration follows loss of the exocrine pancreas in animal experiments (Allan, Bowie, Macleod and Robinson, 1924) and in human disease such as congenital hypoplasia of the exocrine pancreas (Clarke and Hadfield, 1924; Davie, 1938) and lithiasis of the gland (Sanes, Miller, Brason and Geist, 1950). The infiltration leads in turn to a fine diffuse fibrosis (Chaikoff, Connor and Biskind, 1938; Himsworth, 1947; Sanes et al., 1950). The train of events in fibrocystic disease, however, is quite different and it is clear that the patchy scarring of the liver in cases like the present one is not caused simply by pancreatic deficiency. Indeed, when cirrhosis is present the function of the pancreas is often remarkably preserved and active exocrine tissue seems to persist longer than in the majority of cases of the disease. In the present instance three years before splenomegaly was detected tryptic activity was so high in the duodenal juice that a diagnosis of fibrocystic disease was not made then. The liver, however, was palpable and lesions were probably present at that time. Two out of Webster and Williams' (1955) five cirrhotic cases and both of the cases of Di Sant' Agnese (1955) also showed considerable tryptic activity in the duodenal juice and in one of the latter the gradual onset of the pancreatic failure was traced by serial estimations. A biopsy taken from that patient while pancreatic function was still adequate showed a relatively normal gland with an increased amount of fibrous tissue and an early inflammatory reaction. Despite 


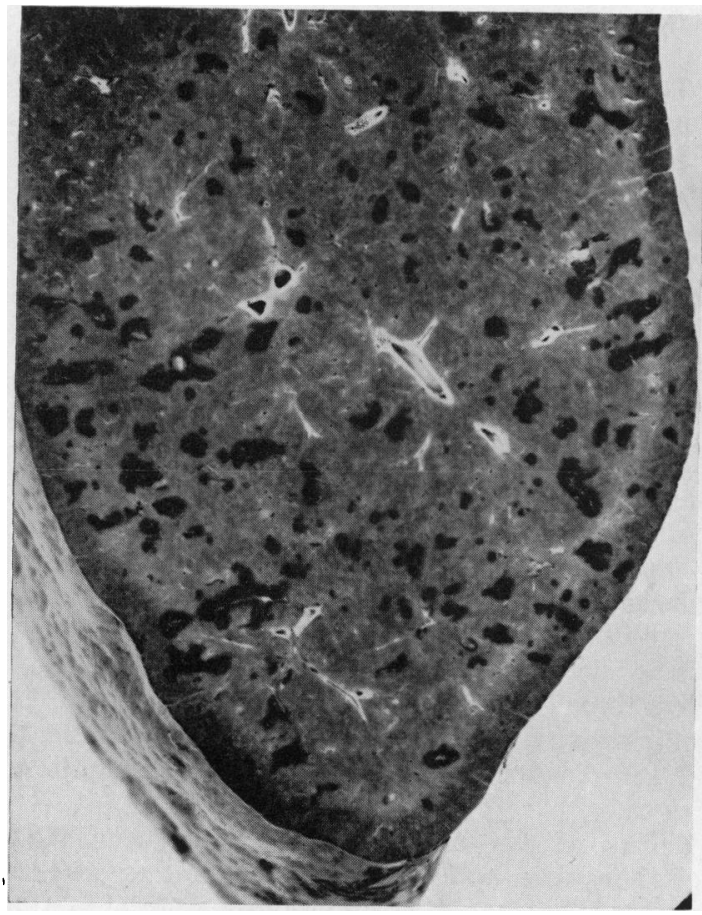

Fig. 1.-The enlarged spleen. Irregular brown areas containing fibrous tissue and haemosiderin (Gamna-Gandy bodies) surround blood vessels. The red pulp is greatly increased. The surface is finely puckered $\left(\times 1 \frac{1}{3}\right)$.

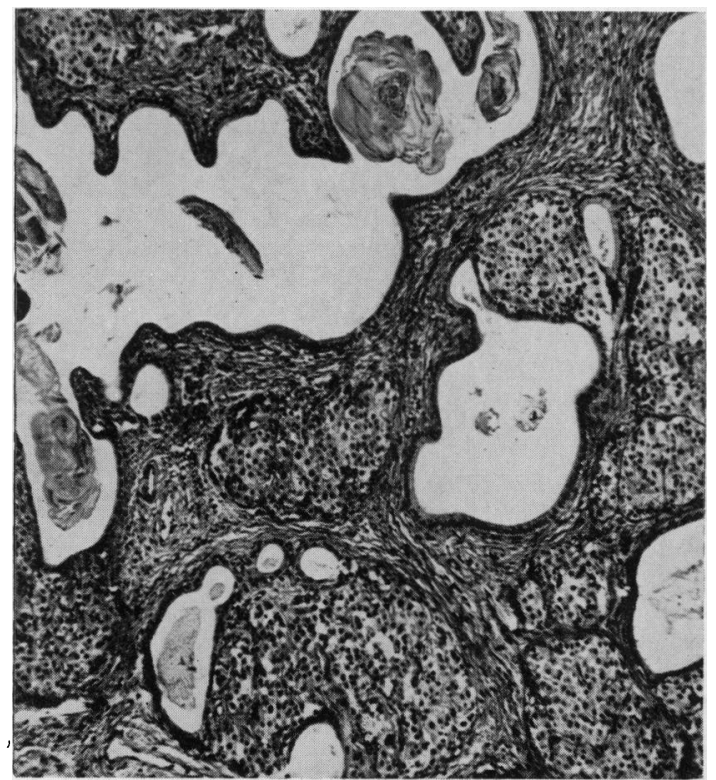

Fig. 2.-Pancreatic biopsy. In this nodule the ducts are dilated and contain dense laminated material. Islet tissue is hypertrophied, fibrous tissue is moderately increased and acinar tissue is greatly reduced. There is no inflammatory exudate (haematoxylin and eosin $\times 85$ ).

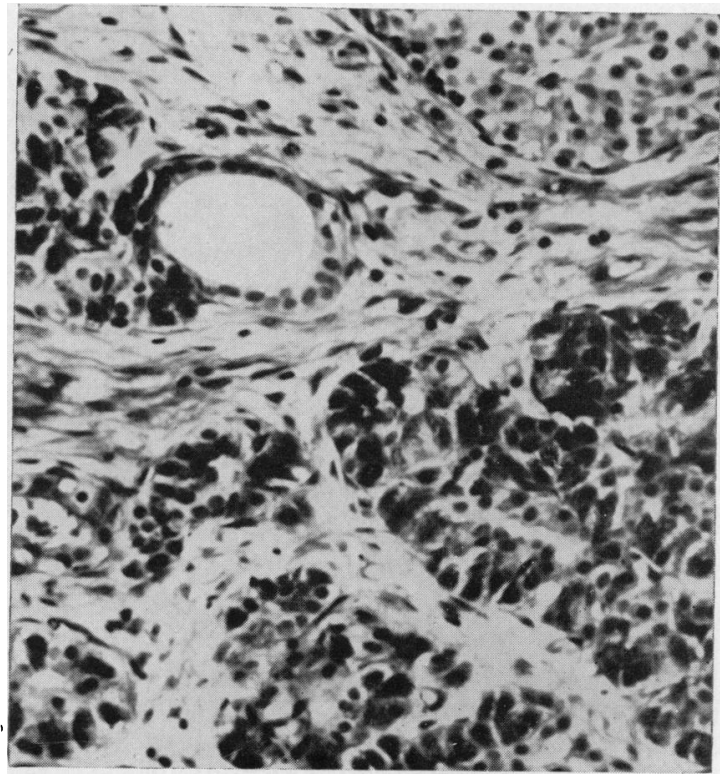

FIG. 3.-Pancreatic biopsy. An hypertrophied islet is shown, top right, and below it a dilated duct. Fibrous tissue is increased. Acinar tissue, present in much of the field, is somewhat atrophied (Mann's stain $\times 150$ )

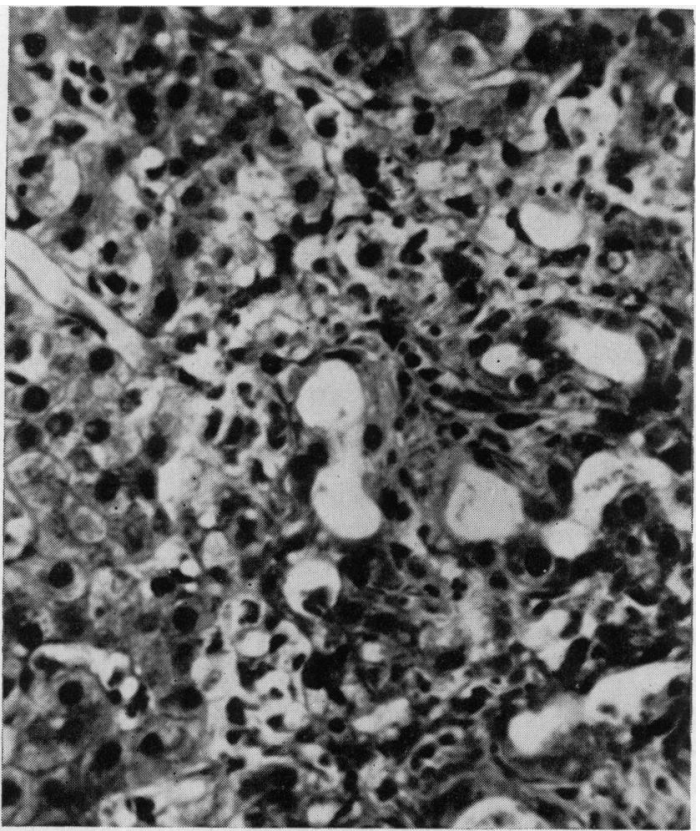

Fio. 4.- - Liver biopsy. In this portal tract, bile ducts are increased in number and dilated. There is an increase in fibrous tissue and in the vascularity of the tract and a minor lymphocytic infiltration. Liver tissue, top and left, shows no marked changes here. (Haematoxylin and eosin $\times 400$ ). 
the biopsy finding of inflammatory changes in their own case the authors favour the view that blockage of the pancreatic ducts by inspissated secretions precedes degeneration of the parenchyma. The histology of the biopsy in our case, which tends to confirm this view, is of interest in showing dilatation of the ducts and inspissated secretions in a portion of the pancreas of a child whose pancreatic function was relatively good three years before. It apparently represents an intermediate stage in the evolution of the pancreatic lesion, and the absence of inflammatory reaction and the relatively minor degree of fibrosis are noteworthy. The hyperplasia of islet cells cannot be explained fully, though no doubt loss of acinar tissue has concentrated the surviving islets. It is not clear how this phenomenon is related to the main process but it probably accounts for the nodularity of this piece of tissue seen at operation. The biopsy differs in this and other points from the usual specimens removed at necropsies on younger patients. The pancreas in the case of Pugsley and Spence (1949), a 17-year-old boy, also showed unusual features. It is not to be expected that lesions first developing in the mature pancreas of the older child with cirrhosis would take the same form as those in the immature organ of more severely affected children in infancy. While some form of duct obstruction would appear to be essential to the pathogenesis of the pancreatic lesion of all ages, the presence of inflammation probably hastens its development as Claireaux (1956) suggests.

The fibrocystic changes in the pancreas are only part of a general upset of the exocrine glands of the body, and the introduction of sodium and chloride determinations as a diagnostic procedure (Di Sant' Agnese, Darling, Perera and Shea, 1953) has allowed atypical forms of the disease like that reported here to be recognized during life. Cirrhosis has been added to the dangers to which the patients are exposed but even in such cases it is respiratory infection which probably remains the most serious threat, generally causing death before liver function is grossly affected. Plasma protein levels and the bromsulphthalein were normal in the present case and similar findings are reported by Webster and Williams (1953) and Di Sant' Agnese (1955). The liver lesion, though progressive, has had more serious effects up to date on the portal circulation than on the liver cells and the possibility of haematemesis is as great as in any other type of portal hypertension. The spleen was larger than any we have seen in portal obstruction at this age, and though traumatic rupture is uncommon in portal hypertension, the organ was considered a danger to this patient who is an active schoolboy.

Di Sant' Agnese (1956) recommends a shunt operation for portal hypertension in fibrocystic disease but a splenectomy was considered adequate in the present instance because oesophageal varices had not been demonstrated, and because of our relatively favourable experience of the simpler operation in portal hypertension. A shunt may be performed at a later date.

\section{Summary}

A case of fibrocystic disease is reported in a 9-year-old boy in which gross splenomegaly resulting from cirrhosis and portal hypertension was treated by splenectomy. The fibrocystic disease had progressed slowly and a specimen of duodenal juice taken three years previously showed considerable tryptic activity. A respiratory infection was present and the diagnosis was confirmed by examination of sweat.

Biopsy of the pancreas showed unusual histological features but also marked dilatation of the ducts and inspissation of secretions.

Biopsies of the liver did not show any fatty infiltration of that organ; cirrhosis in fibrocystic disease is not brought about in this way and is not simply the result of destruction of the exocrine pancreas. Biopsies and liver function tests suggest that focal obstruction of bile ductules is the prime lesion. The main danger of liver disease in this condition is portal hypertension.

We are indebted to Dr. Muriel Frazer under whose care the patient came first, for kindly making her case notes available. We also wish to thank Professor J. H. Biggart for help and advice and Mr. D. Mehaffey for the photomicrographs.

\section{REFERENCES}

Allan, F. N., Bowie, D. J., Macleod, J. J. R. and Robinson, W. L. (1924). J. Exp. Path., 5, 75.

Bodian, M. (1952). Fibrocystic Disease of the Pancreas, pp. 104-110, London.

British Medical Journal (1956). Leading article, 2, 648.

Chaikoff, I. L., Connor, C. L. and Biskind, G. R. (1938). Amer. J. Path., 14, 101.

Claireaux, A. E. (1956). Archives of Disease in Childhood, 31, 22.

Clarke, C. and Hadfield, G. (1924). Quart. J Med., 17, 358.

Davie, T. B. (1938). J. Path. Bact., 46, 473.

Di Sant' Agnese, P. A. (1955). Pediatrics, 15, 683.

(1956). J. Amer. med. Ass., 160, 846.

Darling, R. C., Perera, G. A. and Shea, E. (1953). Pediatrics, $12,549$.

Himsworth, H. P. (1947). Lectures on the Liver and its Diseases, p. 54. Oxford.

Pugsley, M. E. and Spence, P. McK. (1949). Ann. intern. Med., 30,

Sanes, S., Miller, D. K., Brason, F. W. and Geist, O. B. (1950). Arch. intern. Med., 85, 980.

Webster, R. and Williams, H. (1953). Archives of Disease in Childhood, 28, 343 . 